\title{
INJÚRIA PELO FRIO EM FRUTOS DE MAMOEIRO (Carica papaya L.) cv 'GOLDEN’1
}

\author{
ROBSON FERREIRA DE ALMEIDA², EDER DUTRA DE RESENDE ${ }^{3}$, LETÍCIA VITORAZI ${ }^{4}$, LANAMAR DE ALMEIDA \\ CARLOS $^{5}$, LUCIANA KONDA DE AZEVEDO PINTO ${ }^{6}$, HUGO RAFAEL FONSECA DA SILVA ${ }^{6}$, \\ MEIRE LELIS LEAL MARTINS ${ }^{7}$
}

\begin{abstract}
RESUMO - Os sintomas da injúria pelo frio em frutos de mamoeiro cv 'Golden' foram investigados neste trabalho.Os frutos apresentando de 10\% a $15 \%$ de coloração amarela na casca, foram classificados na linha de operação de embalagem da Caliman Agrícola S.A(Linhares-ES) e após receberam tratamentos térmicos e químicos. Os frutos foram embalados com filmes plásticos e estocados a $6^{\circ} \mathrm{C}$ e $13^{\circ} \mathrm{C}(85-95 \%$ UR) em uma incubadora (BOD) por 30 dias. Em intervalos de tempo definidos, seis frutos foram analisados quanto à firmeza, mudança de cor e aparência. A firmeza foi analisada tanto na região mais externa quanto na região mais interna do mesocarpo. De acordo com os resultados encontrados, os frutos estocados a $6^{\circ} \mathrm{C}$ apresentaram os sintomas de escurecimento da casca entre o sexto e o décimo segundo dia de estocagem e também não perderam a cor verde após trinta dias de estocagem, conforme identificado pelos parâmetros de Hunter $\boldsymbol{L}$ (luminosidade), Hunter $\boldsymbol{a}$ (degradação da clorofila) e Hunter $\boldsymbol{b}$ (amarelecimento). A firmeza foi drasticamente reduzida nos seis primeiros dias de estocagem nas duas temperaturas. Contudo, ela permaneceu mais elevada na parte externa do mesocarpo durante todo o período de estocagem à $13^{\circ} \mathrm{C}$. Os frutos estocados à $6^{\circ} \mathrm{C}$ mostraram um aumento na firmeza, nas duas partes do mesocarpo, entre o sexto e o décimo oitavo dia de armazenamento devido à incidência da injúria pelo frio.
\end{abstract}

Termos para indexação: injúria pelo frio, mamão, estocagem refrigerada, amadurecimento

\section{CHILLING INJURY IN PAPAYA FRUITS (Carica papaya L.) CV 'GOLDEN'}

\begin{abstract}
The symptoms of chilling injury in papaya fruit cv 'Golden' were investigated in this work. Fruits presenting $10 \%$ to $15 \%$ of fruit skin yellowing were sorted in the packaging line of the Caliman Agrícola S.A(Linhares-ES), after received chemical and heat treatments. The fruits were wrapped in a plastic film and stored at temperatures of $6^{\circ} \mathrm{C}$ and $13^{\circ} \mathrm{C}(85-95 \% \mathrm{RH})$ in an incubator (BOD) for 30 days. At defined time intervals, six fruits were evaluated regarding to firmness, appearance and color change. The fruit firmness was evaluated as in the outer as in the inner mesocarp halves. According to the results found, the fruits stored at $6^{\circ} \mathrm{C}$ presented skin scald symptoms between six and twelve days of storage and failure to ripen after thirty days, as identified by the Hunter $\boldsymbol{L}$ (luminosity), Hunter $\boldsymbol{a}$ (loss of chlorophyll) and Hunter $\boldsymbol{b}$ (yellowing). The firmness showed a high decrease in the six days of storage in both storage temperatures. However, it stayed higher in the outer mesocarp during all the storage period at $13^{\circ} \mathrm{C}$. Fruits stored at $6^{\circ} \mathrm{C}$ showed an increment in firmness in both mesocarp halves between six and eighteen days of storage due to the chilling injury incidence. Index terms: chilling injury, papaya, refrigerated storage, ripening
\end{abstract}

\section{INTRODUÇÃO}

O processo de deterioração de frutas tem, de maneira geral, como causas principais, o próprio processo de senescência, as injúrias mecânicas, os danos causados por microrganismos e por outros seres, as alterações químicas e os distúrbios fisiológicos (Abeles et al., 1992). A velocidade e a intensidade com que estas alterações ocorrem, são dependentes das características genotípicas, das condições edafoclimáticas de cultivo, condições de colheita e de armazenamento (Kader et al., 1989; Brackmam et al.,1995).

A injúria pelo frio é uma desordem fisiológica observada nos tecidos das plantas, principalmente naquelas de origem tropical e subtropical. É resultante da exposição dos tecidos a temperaturas de refrigeração abaixo da crítica, causando danos fisiológicos aos frutos. A temperatura crítica em que os sintomas ocorrem varia de acordo com as cultivares (Couey, 1982). Além disso, os frutos em estádios de maturação mais avançados são mais resistentes ao aparecimento deste distúrbio (Chen \& Paull, 1986).

O desenvolvimento dos sintomas da injúria pelo frio é mais severo em produtos sensíveis ao abaixamento de temperatura. A sua manifestação está relacionada com o tempo e a temperatura de exposição dos frutos (Couey, 1982). Os sintomas podem ser vários, como as lesões de superfície (escurecimento, áreas afundadas, despigmentação), exsudação da polpa, inibição do amadurecimento, aceleração da senescência, aumento, suscetibilidade à contaminação (Morris, 1982). Em pêssegos, os sintomas provocados pela injúria ao frio foram caracterizados pela textura gelatinosa, aspecto vítreo da polpa e uma coloração de avermelhada para negra na casca dos frutos (FernandezTrujillo et al., 1998).

Embora exista um grande número de variáveis que podem afetar a severidade e a intensidade da injúria pelo frio, geralmente os sintomas são similares. A injúria pode afetar a parte estrutural dos frutos, como, por exemplo, os cloroplastos e a mitocôndria. Estas organelas podem sofrer desorganização, dilatação dos tilacóides, formação de pequenas vesículas no cloroplasto e acúmulo de gotículas de lipídios no cloroplasto (Jagels, 1970). As primeiras manifestações da injúria ao frio são o aumento de tamanho do cloroplasto e a desordem causada nos tilacóides. Prolongados períodos sob temperaturas que causam a injúria, levam ao acúmulo de gotículas de lipídios e ao escurecimento no estroma, além da desintegração da membrana que envolve o cloroplasto. Pode também ocorrer mistura do conteúdo do estroma com o citoplasma e diminuição do conteúdo de amido (Jagels, 1970).

A temperatura mínima para o armazenamento do mamão é determinada pela sua suscetibilidade à injúria ao frio. Temperaturas compreendidas entre $9 \mathrm{e} 12{ }^{\circ} \mathrm{C}$ são geralmente as mais utilizadas para o seu armazenamento, dependendo de fatores como estádio de maturação, tipo de cultivar e condições ambientais de produção (Chen \& Paull, 1986). Durante a estocagem do mamão sob refrigeração, várias alterações metabólicas são observadas, como mudanças na taxa respiratória (Abou Aziz et al., 1975), alteração dos conteúdos de clorofila e carotenóides na casca (Abou Aziz et al., 1975; An \& Paul, 1990), redução de firmeza da polpa e aumento da perda de peso (Chen \& Paull, 1986; An \& Paull, 1990).

Neste contexto, este trabalho teve por objetivo verificar a incidência da injúria causada pelo frio nos frutos de mamoeiro (Carica

\footnotetext{
1 (Trabalho 071/2004). Recebido: 08/06/2004. Aceito para publicação: 19/04/2005. Suporte Financeiro: CAPES, FAPERJ, FINEP. rfdealmeida@yahoo.com.br.

${ }^{3}$ Professor Associado, LTA/CCTA/UENF, Tel (22) 27261461, e-mail: eresende@uenf.br (autor para correspondência).

${ }^{4}$ Licenciatura em Química (IC-PIBIC/CNPq), LTA/CCTA/UENF, vitorazi@uenf.br.

${ }^{5}$ Técnica Nível Superior, LTA/CCTA/UENF.

${ }^{6}$ Mestre em Produção Vegetal, LTA/CCTA/UENF.

${ }^{7}$ Professora Associada, LTA/CCTA/UENF, Tel (22) 27261460, e-mail: meire@ uenf.br.
}

${ }^{2}$ Mestrado em Produção Vegetal, LTA/CCTA/UENF, Av. Alberto Lamego, 2000, Parque Califórnia, Campos dos Goytacazes (RJ), CEP: 28013-600, e-mail: 
papaya) cultivar 'Golden', que é um mutante derivado da cultivar 'Sunrise Solo', selecionado no Espírito Santo, que tem apresentado grande aceitação comercial. Esta cultivar mostra características distintas dos frutos da cultivar original, sendo mais claros e com tendência a ter menor severidade de manchas fisiológicas na casca, que tanto depreciam a cultivar 'Sunrise Solo' (Fonseca, 2002).

\section{MATERIAL E MÉTODOS}

Frutos de mamoeiro (Carica papaya L.) cv 'Golden' foram selecionados na seção de classificação da Empresa Caliman Agrícola S.A. (Linhares-ES), após passarem por tratamentos químicos e banho hidrotérmico $\left(48^{\circ} \mathrm{C} / 20 \mathrm{~min}\right)$. Os frutos selecionados encontravam-se em estádio de maturação com aproximadamente 10-15\% de cor amarela da casca e um padrão de tamanho de aproximadamente $500 \mathrm{~g}$. Após a seleção, os mamões foram transportados sob refrigeração para o Laboratório de Tecnologia de Alimentos (LTA/CCTA) da Universidade Estadual do Norte Fluminense, onde os experimentos foram realizados.

Os frutos foram embalados individualmente em copolímeros laminados Xtend ${ }^{\mathrm{TM}}$-PP7 (StePac L.A.) de $30 \mathrm{~cm}$ de comprimento e $20 \mathrm{~cm}$ de largura. Posteriormente, foram armazenados a $6^{\circ} \mathrm{C}$ e $13^{\circ} \mathrm{C}(85 \%-95 \%$ UR) em incubadoras dotadas de sistema de ventilação forçada (BOD), marca Marconi, modelo MA415, por 30 dias. Após intervalos definidos de tempo, 6 frutos foram aleatoriamente retirados de cada incubadora e analisados quanto à aparência geral, coloração da casca e firmeza da polpa.

A coloração da casca dos frutos foi determinada através do colorímetro de Hunter, modelo Hunterlab Miniscan Spectophotometer (Oliveira, 2002). As medidas foram feitas em quatro pontos distintos, na parte equatorial dos frutos. Os resultados foram expressos na proporção dos parâmetros de Hunter $(L)$, que indica o escurecimento da casca, parâmetro de Hunter $(a)$, que indica a perda da cor verde e parâmetro de Hunter $(b)$, que mostra a evolução da cor amarela.

As medidas de firmeza da polpa foram feitas na região equatorial do fruto, em quatro pontos eqüidistantes das partes externa e interna do mesocarpo, caracterizando alterações no sentido radial do mesocarpo do fruto (Almeida, 2003). As análises foram conduzidas com um penetrômetro digital, marca Turoni ${ }^{\mathrm{R}}$ (Italy), modelo 53205, e as medidas foram expressas em Newton (N).

$\mathrm{O}$ delineamento experimental adotado foi o inteiramente casualizado, em esquema fatorial $2 \times 2 \times 6$. Os fatores estudados foram 2 temperaturas de armazenamento $\left(6^{\circ} \mathrm{C}\right.$ e $\left.13^{\circ} \mathrm{C}\right), 2$ regiões distintas do mesocarpo e 6 períodos de armazenamento $(0 ; 6 ; 12 ; 18 ; 24$ e 30 dias $)$, com 6 repetições. Os dados coletados foram submetidos à análise de variância e as médias comparadas pelo Teste de Tukey, ao nível de 5\% de probabilidade.

\section{RESULTADOS E DISCUSSÃO}

Os sintomas mais comuns da injúria pelo frio, em frutos de mamoeiro, foram o escurecimento e o afundamento de pequenas áreas da casca. Além disso, o amadurecimento dos frutos foi retardado, e os mesmos apresentaram uma coloração manchada (Couey, 1982).

O escurecimento da casca dos frutos da cultivar Golden ocorreu entre o sexto e o décimo segundo dia de estocagem a $6^{\circ} \mathrm{C}$ (Tabela 1). Análises subjetivas da cor e registros fotográficos (dados não apresentados) indicaram que a incidência da injúria pelo frio ocorreu de maneira expressiva na face do fruto que permaneceu exposta à insolação no campo, durante a sua ontogenia, sendo estes resultados similares aos encontrados por Silva et al. (2003). Segundo estes autores, a exposição de determinada região do mamão ao sol, contribuiu para o aparecimento da incidência da injúria pelo frio.

$\mathrm{O}$ afundamento de pequenas áreas da casca do mamão foi observado após o décimo oitavo dia de armazenamento a $6^{\circ} \mathrm{C}$, coincidindo com uma tendência de redução da firmeza da polpa (Tabela 2). Estes resultados podem ser atribuídos ao aumento da atividade da enzima poligalacturonase, que hidrolisa componentes da parede celular, como as substâncias pécticas, responsáveis pela firmeza da polpa (Karakurt \& Huber, 2002). Estas substâncias, que constituem a parede celular do tecido, podem ser formadas através de rotas alternativas induzidas pela enzima fenilalanina amonialiase, em resposta ao estresse fisiológico do frio no tecido (Silva, 2003). No presente trabalho, o sintoma de escurecimento da casca ocorreu entre o sexto e o décimo segundo dia de estocagem a $6^{\circ} \mathrm{C}$ (Tabela 1). Análises subjetivas da cor e registros fotográficos indicaram que a incidência da injúria pelo frio ocorre de maneira expressiva na face do fruto que permaneceu exposta ao sol, na planta, durante a sua ontogenia.

A análise da coloração da casca pelo Colorímetro de Hunter mostrou que a luminosidade (parâmetro de Hunter $L$ ) aumentou durante a estocagem a $13^{\circ} \mathrm{C}$, conforme mostrado na Tabela 1 . Destaca-se que, entre 24 e 30 dias de estocagem, ocorreu incidência de fungos que

TABELA 1 - Medidas de coloração da casca de frutos de mamoeiro (Carica papaya L.), armazenados a $6^{\circ} \mathrm{C}$ e $13^{\circ} \mathrm{C}$ durante 30 dias, caracterizadas pelos parâmetros de Hunter $L, a, b^{1}$.

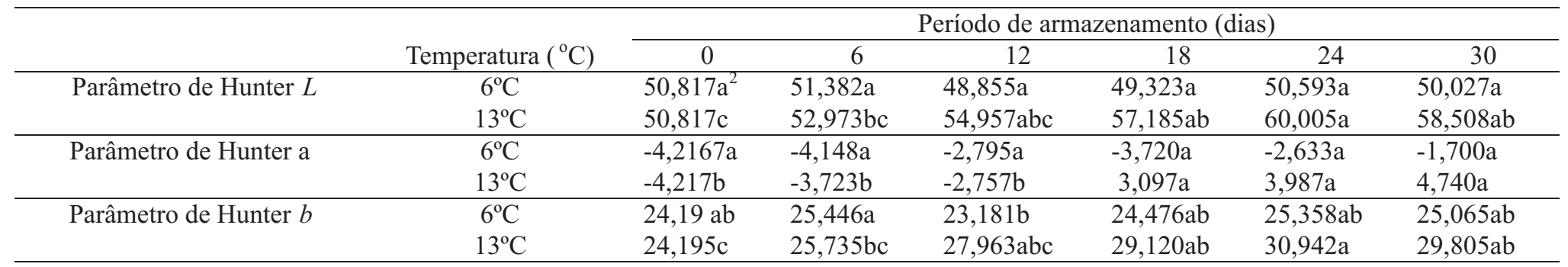

${ }^{1}$ Parâmetro de Hunter L (luminosidade), Hunter b (perda da cor verde), Hunter a (amarelecimento)

${ }^{2}$ Médias seguidas de uma mesma letra nas linhas não diferem entre si, pelo teste de Tuckey, ao nível de 5\% de probabilidade.

TABELA 2 - Médias de firmeza da parte externa (E) e interna (I) do mesocarpo de frutos de mamoeiro (Carica papaya $\mathrm{L}$.), armazenados a $6^{\circ} \mathrm{C}$ e1 $3^{\circ} \mathrm{C}$, durante 30 dias.

\begin{tabular}{|c|c|c|c|c|c|c|c|}
\hline \multirow[t]{2}{*}{ Temperaturas $\left({ }^{\circ} \mathrm{C}\right)$} & \multirow[t]{2}{*}{ Mesocarpo $^{1}$} & \multicolumn{6}{|c|}{ Período de armazenamento (dias) } \\
\hline & & 0 & 6 & 12 & 18 & 24 & 30 \\
\hline \multirow[t]{2}{*}{6} & E & $77,68 \mathrm{Aa}^{2}$ & $32,86 \mathrm{Ab}$ & $45,27 \mathrm{Ab}$ & $52,31 \mathrm{Aab}$ & $38,42 \mathrm{Ab}$ & $32,257 \mathrm{Ab}$ \\
\hline & I & $48,29 \mathrm{Ba}$ & $18,09 \mathrm{Ac}$ & $25,52 \mathrm{Abc}$ & $37,24 \mathrm{Aab}$ & $25,48 \mathrm{Abc}$ & $10,507 \mathrm{Bc}$ \\
\hline \multirow[t]{2}{*}{13} & $\mathrm{E}$ & $77,68 \mathrm{Aa}$ & $11,368 \mathrm{Ab}$ & $10,582 \mathrm{Ab}$ & $12,497 \mathrm{Ab}$ & $6,413 \mathrm{Ab}$ & $7,200 \mathrm{Ab}$ \\
\hline & I & $50,45 \mathrm{Ba}$ & $5,683 \mathrm{Bb}$ & $5,475 \mathrm{Bb}$ & $4,717 \mathrm{Bb}$ & $4,615 \mathrm{Bb}$ & $3,995 \mathrm{Bb}$ \\
\hline
\end{tabular}

${ }^{1} \mathrm{E}$ (parte externa), I (parte interna)

${ }^{2}$ Médias seguidas de uma mesma letra minúscula nas linhas e maiúsculas nas colunas, para cada temperatura, não diferem entre si, pelo teste de Tuckey, ao nível de $5 \%$ de probabilidade. 
reduziram as medidas de luminosidade da casca. De outra maneira, os valores médios do índice de luminosidade mostraram uma tendência de redução nas medidas entre o sexto e o décimo segundo dia de estocagem a $6^{\circ} \mathrm{C}$, indicando a incidência da injúria pelo frio neste período.

Em relação ao parâmetro de Hunter $a$, foi observado que os frutos estocados a $13^{\circ} \mathrm{C}$ perderam totalmente a tonalidade verde, sendo que a transformação mais intensa da cor ocorreu entre o décimo segundo e o décimo oitavo dia de armazenamento. Entretanto, os frutos estocados a $6^{\circ} \mathrm{C}$ mantiveram a pigmentação verde durante todo o período de armazenamento, conforme indicado pelos valores negativos do parâmetro de Hunter $a$. O processo de alteração da cor verde pode ser explicado pela degradação da clorofila pelas clorofilases (Chitarra \& Chitarra, 1990). Uma vez que a temperatura influencia no metabolismo do fruto, seu abaixamento diminui a degradação da clorofila, devido à redução da biossíntese e da ação direta do etileno (Abeles et al., 1992).

Ainda em relação aos resultados apresentados na Tabela 1, foi observado que os frutos estocados a $13^{\circ} \mathrm{C}$ mostraram uma evolução da cor amarela durante o armazenamento, culminando no amadurecimento do fruto, sendo que a presença de fungos provocou uma redução do parâmetro de Hunter b, entre 24 e 30 dias de estocagem a $13^{\circ} \mathrm{C}$. Estes resultados corroboram aqueles de Oliveira et al. (2002), que identificaram uma escala de cor durante os estádios de amadurecimento da cultivar 'Golden'. Entretanto, os frutos estocados a $6^{\circ} \mathrm{C}$ não mostraram uma evolução da cor amarela, ocorrendo até mesmo uma redução do parâmetro de Hunter $b$, entre o sexto e o décimo segundo dia de estocagem. Este comportamento é devido, provavelmente, à interferência do processo de escurecimento que iniciou neste período. Na temperatura de $6^{\circ} \mathrm{C}$, pode ter ocorrido uma minimização da biossíntese de pigmentos amarelos e da ação direta do etileno (Abeles et al., 1992).

A análise da firmeza da polpa dos frutos estocados a $13^{\circ} \mathrm{C}$ revelou uma redução acentuada deste parâmetro nos seis primeiros dias de armazenamento (Tabela 2). Além disso, foi observado que esta redução ocorreu nas duas partes do mesocarpo, sendo que até o trigésimo dia de armazenamento a parte externa permaneceu mais firme do que a parte interna.

Os frutos estocados a $6^{\circ} \mathrm{C}$ também mostraram uma redução acentuada da firmeza nos seis primeiros dias. Entretanto, ocorreu um aumento posterior deste parâmetro até o décimo oitavo dia de armazenamento, podendo ser devido à incidência da injúria pelo frio observada neste período em questão. O enrijecimento do tecido pode ser atribuído ao aumento da atividade da fenilalanina amonialiase, que tem uma via alternativa para síntese de substâncias pécticas que conferem maior firmeza à polpa (Hugh, 1984).

Resultados similares de amaciamento de polpa de mamão, nos primeiros dias de estocagem, foram encontrados por Silva (1995). Segundo este autor, frutos de mamoeiro embalados em filme de polietileno de baixa densidade e armazenados a $10^{\circ} \mathrm{C}$ apresentaram uma redução de $45 \%$ de sua firmeza nos seis primeiros dias de estocagem. Além disso, Tijskens et al. (2001) relataram que a firmeza de pêssegos armazenados em diferentes temperaturas, por um período de 35 dias, diminuiu na primeira semana de estocagem. Eles também observaram que a atividade da enzima poligalacturonase, também responsável pela degradação de substâncias pécticas, aumentou nos estágios iniciais de estocagem.

Ainda em relação à firmeza da polpa do mamão, foi observado que a parte externa apresentou valores maiores que a interna. De fato, a maturação do mamão é mais intensa na parte mais interna do mesocarpo, decrescendo daí até o epicarpo (Embrapa, 2002). Draetta et al. (1975) e Paull \& Chen (1983) observaram que, na polpa do mamão, ocorre um gradiente radial de atividade das enzimas responsáveis pela degradação da parede celular. Segundo estes pesquisadores, as enzimas apresentam maior atividade na região do endocarpo.

\section{CONCLUSÕES}

1. Os frutos de mamoeiro cv 'Golden' apresentaram sintomas de injúria pelo frio durante o período de seis a doze dias de estocagem a $6^{\circ} \mathrm{C}$, sendo caracterizados pelo escurecimento da casca. Além disso, outros sintomas foram observados, como o incremento da firmeza entre o sexto e o décimo oitavo dia, o aparecimento de áreas afundadas na casca a partir do décimo oitavo dia e a falha de amadurecimento até o trigésimo dia de estocagem. Os frutos armazenados a $13^{\circ} \mathrm{C}$ amadureceram regularmente.

2. A firmeza da polpa reduziu drasticamente nos seis primeiros dias de estocagem refrigerada, sendo que a parte externa do mesocarpo do fruto apresentou maior firmeza durante todo o período de estocagem a $13^{\circ} \mathrm{C}$. Os frutos estocados a $6^{\circ} \mathrm{C}$ apresentaram aumento de firmeza até o décimo oitavo dia, nas duas regiões do mesocarpo, mostrando que o efeito da injúria pelo frio se expressa por todo o mesocarpo.

3. O abaixamento de temperatura reduziu a taxa metabólica dos frutos, minimizando as alterações de cor da casca e o amaciamento da polpa.

\section{AGRADECIMENTOS}

Os autores são gratos à Empresa Caliman Agrícola S.A, pela concessão, seleção e transporte refrigerado dos frutos, à FINEP e à FAPERJ, pelo apoio financeiro, e à CAPES, pela bolsa de estudos.

\section{REFERÊNCIAS}

ABELES, F.B.; MORGAN, P.W.; SALTVEIT JR, M.E. (1992). Fruit ripening abscision and postharvest disorders. In: ABELES, F.B.; MORGAN, P.W.; SALTEVEIT JR, M.E. Ethylene in plant biology. $2^{\text {nd }}$ ed.,California: Academic Press, 1992. cap.6, p.182-221.

ABOU AZIZ, AB.; EL-NABAAWY, S.M.; ZAKI, H.A.. Effect of different temperatures on the storage of papaya fruits and respirational activity during storage. HortScience, Alexandria, v.3, p.173-177, 1975.

ALMEIDA, R.F. Avaliação das características físicas e químicas de frutos de mamoeiro 'Golden' submetidos à Refrigeração. 2003.46f. Dissertação (Mestrado em Produção Vegetal) - Universidade Estadual do Norte Fluminense Darcy Ribeiro, Campos dos Goytacazes, RJ, 2003.

AN, J.; PAULL, R.E. Storage and ethylene influence on ripening of papaya fruit. Journal of the American Society for Horticultural Science, Alexandria, v.115, p.949-953, 1990.

CHEN, N.M., PAULL, R. E. Development and prevention of chilling injury in papaya fruit. Journal America Society HortScience, Alexandria, v. 114, n.4, p.639-643, 1986.

CHITARRA, M.I.F; CHITARRA, A.B. Pós-colheita de frutos e hortaliças: fisiologia e manuseio. Lavras: FAEPE, ESAL. 1990. 293 p.

COUEY, H.M. Chilling injury of crops of tropical and subtropical origin: an overview. HortScience, Alexandria, v.17, n.2, p.158-162, 1982.

DRAETTA, I. DOS S.; SHIMOKOMAKI, M.; YOKOMIZO, Y.; FUJITA, J. T.; MENEZES, H.C. Transformações bioquímicas do mamão (Carica papaya L.) durante a maturação. Coletânea do Instituto de Tecnologia de Alimentos, Campinas, v.6, p.395-408, 1975.

FERNÁNDEZ-TRUJÍLIO J.P.; MARTÍNEZ J.A.; ARTÉS, F. Modified atmosphere packaging affects the incidence of cold storage disorders and keeps "flat" peach quality. Food Research International, Kidlington, v.31, n.8, p.571-578, 1998.

FONSECA, M.J.O. Conservação pós-colheita de mamão (Carica papaya L.) análise das cultivare "Sunrise Solo" e "Golden", sob controle de temperatura e atmosfera. 2002. 177f. Tese (Doutorado em Produção Vegetal) - Universidade Estadual do Norte Fluminense Darcy Ribeiro, Campos dos Goytacazes RJ, 2002.

HUGH, J. D. Phenylalanine ammonia-lyase: Regulation of its induction, and its role in plant development. Phytochemistry, Oxford, v.23, n.7, p.1349-1359, 1984.

JAGELS, R. Photosynthetic apparatus in Selaginella. Changes in plastid ultraestructure and igment content under different light and temperature regimes. Canadian Journal of Botany, Ottawa, v.48, p.1853-1860, 1970. 
KADER, A.A.; ZAGORY, D.; KERBEL, E.L Modified atmosphere packaging of fruits and vegetables. Critical reviews in Food Science and Nutrition, Boca Raton, v.28, n. 1, p.1-30, 1989.

KARAKURT, Y.; HUBER, D.J. Activities of several membrane and cellwall hydrolases, ethylene biosynthetic enzymes, and cell wall polyuronide degradation during low-temperature storage of intact and fresh-cut papaya (Carica papaya) fruit. Postharvest Biology and Technology, Amsterdan, v. 24, p. 1-11, 2002.

MORRIS, L.L. Chilling injury of horticultural crops: an overview. HortScience, Alexandria, v.17, n.2, p.157-158, 1982.

OLIVEIRA, M.A.B.; VIANNI, R.; SOUZA, G.; ARAÚJO, T.M.R. Caracterização do estádio de maturação do papaya 'Golden' em função da cor. Revista Brasileira de Fruticultura, Jaboticabal, v. 24, n. 2, p.559-561, 2002.

PAULL, R.E.; CHEN, N.J. Postharvest variation in cell wall-degradin enzymes of papaya (Carica papaya L.) during fruit ripening. Plant Physiology, Bethesda, v.72, p.382-385, 1983.

SILVA, E.O. Efeito da embalagem plástica e da temperatura sobre a qualidade pós-colheita do mamão. 1995. 79p. Dissertação (Mestrado
Fisiologia Vegetal) - Universidade Federal de Viçosa, Viçosa MG, 1995.

SILVA, H.R.F. Influência da temperatura e da incidência do sol sobre a atividade de algumas enzimas durante a estocagem refrigerada do mamão (Carica papaya L.). 2003. 63f. Dissertação (Mestrado em Produção Vegetal) - Universidade Estadual do Norte Fluminense Darcy Ribeiro, Campos dos Goytacazes RJ, 2003.

SILVA, H.R.F.; RESENDE, E.D.; VITORAZI, L.; PINTO, L.K.A.; MARTINS, M.L.L. Relação entre o escurecimento e a atividade da enzima fenilalanina amonialiase em mamão (Carica papaya $\mathrm{L}$.) armazenado sob refrigeração. In: SIMPÓSIO DO PAPAYA BRASILEIRO, 2003. Vitória-es. Resumos... p. 681-684.

SILVA, M.L. da. Mamão pós-colheita. Brasília: EMBRAPA Informações Tecnológicas, 2002. p.55. (Série Frutas do Brasil, 11).

TIJSKENS, L.M.M.; KONOPACKI, P.; SIMCIC, M. Biological variance in agricultural products. experimental examples. IN: INTERNATIONAL VARIANCE INAGRICULTURALPRODUCTS EXPERIMENTAL EXAMPLES, 8., Proceedings... 2001. p.8-13. 